\title{
Can the Environment Wait in a Developing Country?
}

\section{John A Dixon and Gayatri Acharya}

The World Bank, Washington

\begin{abstract}
Can the environment wait in developing countries? Should countries focus on growth first and worry about cleaning up later? Is there an optimal mix between growth, development, and environmental management? These are all real issues facing the world's community of developing countries. The following presentation suggests that the answer to this question is that the environment does not have to wait.
\end{abstract}

JEL Q28

\section{A TALE OF TWO COUNTRIES}

Azerbaijan and Costa Rica may seem to have little in common and, yet, recent work in both countries provides some interesting comparative, if anecdotal, data.

First, consider Azerbaijan, one of the world's first oil states. A hundred years ago Baku, the capital, and Azerbaijan were an important center of oil production. The oil boom that began at that time resulted in a number of impressive buildings in Baku - grand avenues, an imposing Opera House, an impressive array of mansions and apartments buildings. Just outside Baku, however, one is met by wasteland all along the shores of the Caspian Sea that is the direct result of the oil boom and associated production. Kilometers of rusty pipelines, pools of blue/green/black water and piles of industrial waste line the shore. It is a true environmental disaster, and much valuable Caspian Sea-front real estate is unusable.

Azerbaijan is a classic cautionary tale of the danger of the "grow first, clean up later" mentality. Those who benefited from oil extraction over the decades are gone, lost in time and in changes of governments. Now all that remains from the past oil boom are a number of grand buildings in a very poor country, and a tremendous bill for clean-up or remediation measures. Although new oil production may hold out hope for addressing some of these problems, the new 
developers rightly maintain that they should be held responsible for their actions only, not for the environmental blunders of 10 to 50 years ago. Nonetheless, the costs associated with those blunders will be borne by society at large. Better governance and a different set of political and historical conditions may well have resulted in different outcomes for the country. After all, many of today's developed countries have reached their current levels of economic prosperity despite, and some may argue, because of, over-exploitation of their natural resources. The choices available to countries today are however significantly different due to increased pressure on resources and changes in global, national and local awareness regarding patterns of economic development. Azerbaijan, like other mineral rich countries, faces an interesting choice today of making the most of its oil resources by wisely re-investing the rents from oil exploration in society, thereby achieving more sustainable economic development.

Now consider the case of Costa Rica, a small Central American country that has relied on its natural resources for growth. Originally coffee and bananas were the backbone of the economy, and now tourism - eco or otherwise - forms a major share of the economy. Costa Rica has successfully marketed itself internationally as a green, environmentally-friendly country and receives large numbers of international visitors each year. In its intemational advertising it uses the slogan "Costa Rica - No Artificial Ingredients" to sell itself and reinforce this image.

Costa Rica faces all the problems most middle-income developing countries (including a high deforestation rate). But Cost Rica has successfully identified a strategy to "grow green" and take care of environmental problems to the extent possible, realising that this benefits both the environment and good for the economy. An important part of this process has been a partnership between the government, the people of Costa Rica and the private sector, all of whom realise that they have an incentive in addressing environmental problems and that these problems affect all of them.

\section{IS THERE AN ENVIRONMENT-DEVELOPMENT DICHOTOMY?}

As these two case studies suggest, there are different paths for development for resource-based countries. It has been suggested that the environment is a luxury good for the rich. A related view is that a country should get rich first and worry about the environment later. These hypotheses are now examined. 


\section{The environment as a luxury good}

There is no doubt that in some ways the environment is a luxury good. In economic terms, this merely means that the environment has an income elasticity of demand greater than 1 (that is, if income grows by 10 per cent, demand for a the "environment" will grow by more than 10 per cent). There is no doubt that some uses of the environment are in fact luxury goods - for example, the demand for scuba diving or unique wilderness experiences.

For most other types of environmental goods and services, however, demand is usually positive, if not in the luxury good category. Positive income elasticity merely means that as incomes grow, demand for the environment also grows. As such, the demand for a healthy, cleaner environment will grow as incomes increase. In this sense the environment can be considered as an appreciating economic asset - its value will grow in the future as incomes rise.

In addition, the environment is a central part of their production system for many: farmers, fishermen and loggers all depend directly on the environment to produce income. In fact, it is precisely the poorest who are most directly dependent on the environment as a source of production.

There are also important social-economic linkages between the environment and health and other social factors. In the case of the link between poor water resource management and lack of sanitation, for example, it is found that the negative impacts on health fall heavily on the poorest members of society and that the opportunity costs of time spent collecting drinking water may be much higher than normally thought. In both cases the economic benefits from improved water supplies (both in terms of quality and quantity) may be quite large. The cross-sectoral linkages (especially in terms of health and productivity implications for the poor) of investing in sectors such as water and clean energy are often overlooked by policy makers and growth advocates who suggest that environment is a luxury good.

\section{The "grow first, clean up later" hypothesis}

As mentioned earlier, there is a wide-spread belief that countries should focus on traditionally-measured economic growth first and only be concerned about the environment afterwards. While it is true that this is the growth path followed by the US and much of Europe, this is known to be a sub-optimal approach. This is true for a number of reasons:

Cleaning up after problems have been created (especially from pollution of the air or water) is much more expensive than prevention. Many studies have shown that environmentally friendly development (one that 
minimizes air or water pollution, or natural resource degradation) often only costs 1 to 3 per cent more in initial investment costs (and avoids damages that are much costlier to restore afterwards).

- As seen in Azerbaijan, growing first and cleaning up later often results in no one accepting responsibility for the clean-up - all the funding has dried up and those who created the sinuation are no longer around. The US has implemented an expensive SuperFund program to clean up abandoned toxic and hazardous waste sites all over the country.

- The grow first, clean up later philosophy may also result in extinct species and lost genetic opportunities, which consequence is of a permanent nature.

- Since many environmental problems disproportionately affect the poor, the emphasis on growth without consideration of environmental issues necessarily implies a more limited set of options for poorer communities.

\section{A FALSE DICHOTOMY - BUT A DIFFICULT PATH TO CHARTER}

The supposed Development-Environment Dichotomy is in fact a false dichotomy. The following examples prove this.

The tremendous learning of the past 40 to 50 years has shown that it is possible, both technically and economically, to "grow greener" without large, or in some cases, any additional economic costs. Whereas the famous Environmental Kuznets Curves (EKC) hypothesized that as economies grew the environment would initially suffer and only later improve, it is now clear that there are many possibilities to "tunnel through" the Kuznets curve and grow in an environmentally-friendly manner. This is due to technological change as well as policy intervention. For example, modern transportation and energy production are much less polluting than they were 30 or 50 years ago. Similarly, the advent of the computer and high speed communications means that it may be possible to leap frog certain traditional stages in growth.

Environmental Kuznets Curves (see Figure 1) are also more complex than initially thought. Although the classic EKC shape is shown in the middle two curves, with urban concentrations of particulate matter and sulphur dioxide, other EKCs take quite different forms: populations without access to safe water or sanitation both decline steadily as incomes increase. More troubling however, is that other measures increase directly with income, as seen in the lower two EKCs representing municipal waste per capita and carbon dioxide emissions per capita. For some pollutants, there is no tuming point. 
The original Kuznets curve suggested that a deterioration in income distribution in the early stages of economic growth would be followed by an improvement later. This however, can be a long-term outcome and one that is less than desirable in the face of growing poverty levels across the globe.

Figure 1 Environmental Kuznets curves

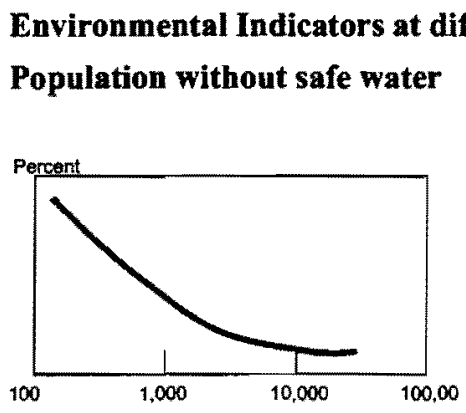

Per capta income (collars, log scale)

\section{Urban concentrations} of particulate matter

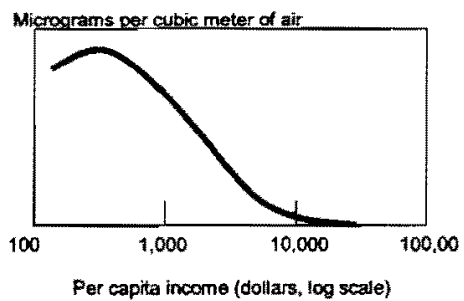

\section{Municipal wastes per capita}

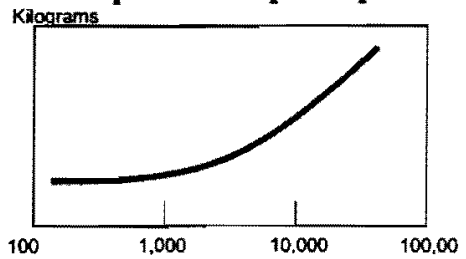

Per capita income (dollars, $\log$ scale)
Urban population without adequate sanitation

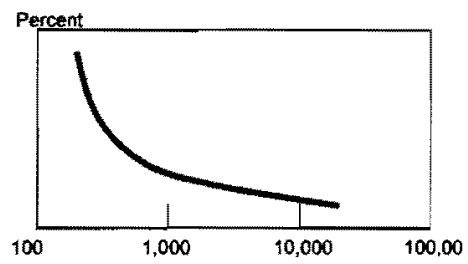

Per capita income (dollars, log scale)

Urban concentrations of sulphur dioxide

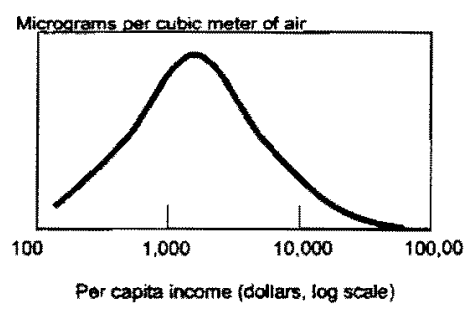

Carbon dioxide emissions per capita

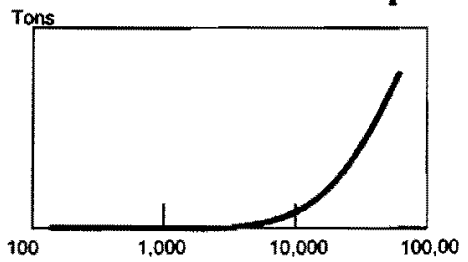

Per capita income (dollars, log scale)

Source: World Bark, World Development Report, 1992 
Similarly, environmental degradation can exacerbate poverty, including vulnerability, and could, in some cases, be irreversible. There is no reason countries should today develop in the same way as they have in the past. A major lesson from the EKC literature is that it is possible to flatten many of the curves via appropriate policy interventions, and that income growth facilitates much of this. The challenge is to grow in a greener manner and reduce unnecessary environmental costs. This thinking is reflected in the natural capitalism literature whereby technological options allow one to switch from high energy/high throughput consumption patterns to lower energy/lower throughput consumption patterns, thereby reducing one's environmental footprint and affecting the shape of the EKCs.

In addition, growth, development and environmental protection can be mutually supportive rather than in conflict in many resource-dependent economies. This can be seen in the ADMADE or Campfire programs in Africa, or in Costa Rica or the tourism-dependent economics in the Caribbean, and community managed programs in India and Nepal; the potential for positive synergies between growth, development and environmental protection clearly exists. The difficulty lies in ensuring that the benefits of such programs reach those communities that are directly dependent on these resources and/or act as caretakers for these resources. The transference of property rights from the state to village communities, and from the individual to communities increasingly proves to be an important factor in addressing both community development needs and environmental quality.

In other locations, the growth of direct payments for ecosystem services can be witnessed. Two well-known examples are those of New York City and Heredia in Costa Rica. In each case the municipal authorities have made direct payments to those who own watershed lands to protect these sources of water supply. In New York, the payments (of several billions of dollars) are used to buy land in the catchment area for New York City and to provide incentives for farmers to reduce the use of agricultural inputs. This should avoid the even larger costs associated with increased treatment of water supplies if the catchment becomes degraded. Before 1996, New York City water was unprocessed and cleansed by the natural filtering services provided by the watershed. Subsequently, with increasing changes in land use, these natural, and free, ecosystem services were damaged by sewage and agricultural externalities. The City estimated a replacement cost of $\$ 10^{10}$ over ten years and initially proposed the building of filtration plants to replace the watershed services. It was however determined that it would be less costly to restore the natural ecosystem, at a cost of $\$ 1.5 \times 10^{9}$ and this is what the city opted for. This example, albeit from a developed country, clearly demonstrates the need to account for alternative options, including investing in natural capital. Without examining the potential net 
benefits associated with alternative investment options, countries may be excluded from more socially efficient development decisions.

Similarly, in Heredia, a small university town in Costa Rica, a small extra charge (measured in cents per cubic meter) is added to the monthly bill of all water users to create a fund that will assist farmers in the catchment area to use less environmentally degrading management practices. This helps to protect the quality and quantity of water coming from the catchment. Various other countries have started to determine systems to evaluate and capture rents associated with ecosystem services that maintain productive and consumptive economic activities.

\section{Developments since Stockholm (1972) and Rio (1992)}

However, even with these positive developments, the challenge of sound environmental management with social and economic growth remains. The Stockholm meeting of 1972 launched the modern environmental movement and Rio, 20 years later, represented its coming of age. Unfortunately, despite the initial optimistic feelings after the 1992 Rio Earth Summit, it is now realized that "growing green" is going to be harder than anyone anticipated. This is true for a number of reasons.

First, even the supposedly easy "win-win" policy changes (i.e. policy measures such as energy or water subsidy reduction, with both economic and environmental benefits, and higher fuel prices for more energy efficient transportation or manufacturing) have proved much harder to implement than envisaged. It turns out that vested interests and politically powerful groups that receive these subsidies, are often able to block subsidy reduction. Governments have often not been willing to take on this politically difficult task, and the costs to the treasury and the environment remains high. This is commonly observed in both developed and developing countries. In the US for example, energy prices have remained low and powerful lobbies successfully oppose even the smallest attempts to increase gasoline prices, thereby reinforcing patterns of living and commuting that are highly energy-inefficient. A World Bank study in 1998, estimated that global fishing subsidies amount to approximately US\$ 11 13.5 billion, while OECD in 1997 estimated total subsidies of US $\$ 6.38$ billion for industrialized countries alone. Trade regulations and restrictions are often used to create trade patterns that encourage inefficiencies in production and consumption, often at the expense of poorer groups.

Second, institutional development has likewise proved much harder than anticipated. Ten or twenty years ago few countries had environmental management institutions - either in government or outside of government. Even 
with major financial and human commitment, it is now realized that the process of building strong, competent environmental management institutions is a longterm undertaking.

Building strong institutions for improved management includes more than training people, passing laws, and building laboratories and an inspection system. It is also necessary to create the political and public support so that these institutions can effectively argue their case with the traditionally powerful ministries that manage finance, the economy, and industrial or agricultural production. In too many countries the Environmental Ministries the weakest portfolios in government and is the environment considered as a second priority. As noted earlier, the cross-cutting issues associated with investing in the environment are often missed by both mainstream development practitioners and by environment advocates.

Third, all too often it has taken a major environmental jolt to focus attention on environmental management. Given the complacency of governments, and the powerful role of vested interests, it has unfortunately often required a powerful joit or a disaster, to focus public and private attention on the role of the environment. The infamous "killer fogs" of London in 1952 led to important work on identifying the links between air pollution and health outcomes; Chernobyl and Bhopal focused attention on industrial pollution and accidents, and the full potential implication of nuclear power. Landslides and flooding in countries around the world (Nicaragua, Turkey and China among many others) focused attention on the links between land use patterns, location of settlements, and susceptibility to land slides and mass destruction. These are expensive (in terms of lives and economic activity) ways to focus attention on the links between the environment and sustainable economic growth.

\section{EIGHT REASONS WHY THE ENVIRONMENT CANNOT WAIT IN DEVELOPING COUNTRIES}

This quick overview of some of the links between economic growth and the environment, highlighting both the positive dimensions and the internal tensions, illustrates the magnitude of the environment/development challenge. Experiences of countries around the world support the view that it is a false dichotomy to consider the environment and development in conflict. In fact, they can be and should be mutually supportive. This optimistic view is supported as follows:

1. The environment is a major economic asset. Whether it is for direct production of food or fiber, or for indirect production of value through 
cleaner air or water, or for sale via tourism, the environment is an important economic asset that plays a central role in the economic health and sustainability of most countries. For some countries, like many of the small Caribbean islands, the environment is their main economic asset and its sale via tourism accounts for 30 per cent to 60 per cent of their GDP. Any economic asset of this importance needs investment in management and maintenance.

2. Prevention is cheaper than cure. Experience around the world convincingly demonstrates that it is cheaper to prevent environmental pollution (or resource degradation) than to try to correct the same problems after they have happened. Many studies have shown that prevention costs usually only add 1 to 3 per cent to initial capital costs, while damages from degraded environments or pollution often result in 5 or 8 or more per cent in annual losses of national GDP. The problem is complicated by the fact that the investment costs are borne by individuals or firms now while the damages that are potentially avoided accrue to a much wider group in the population over a longer period of time.

3. Private gains from the use of the environment are often sufficient to pay the costs to avoid externalities. Just as prevention is cheaper than cure at the national level, the potential benefits to individuals and private firms from use of the environment are often sufficiently large to allow appropriate costs for environmental management or pollution reduction and still profit. This form of the "polluter-pays-principle" means that improved environmental management is often funded by the private sector, provided that governments are tough, perform the appropriate analyses, and act as the stewards of the nation's environment. A major example of the potential for this approach is in such areas as recreation or tourism, whereby tourism operators, tourists and the government are all part of a partnership with shared responsibility for environmental management.

4. Equity issues matter - environmental degradation hurts the poor more than the rich. Environmental degradation generally affects the poor the more. Either they are directly dependent on the soil or the seas for their livelihood, or they are disproportionately affected by polluted air or water. In any case, there is a strong equity argument for improved environmental quality. The rich can often protect themselves from environmental pollution by means of appropriate housing or life-style adjustments. The poor often do not have similar options and governments must frequently intervene on their behalf. One must be careful not to confuse the desire for improved environmental quality (the demand side) 
with the ability to pay for it (the supply side), especially among poor people. Furthermore, access to environmental resources and improved options for income generation are critical for reducing income inequality and vulnerability of the poor.

5. Healthy economies need healthy environments for sustained streams of individual and social benefits. The links between healthy natural environments and production, and the links between clean air and water and health, are widely observed. Healthy environments support healthy economic growth. The converse is also true; poor economics are often characterized by bad environmental quality and poor health. Although the direction of causality is often debated in the literature - do poor people create degraded environments or do degraded environments create poor people? - it is very clear that as incomes grow, people and societies demand (and have the ability to pay for) cleaner environments.

6. Partnerships that promote environmental issues are likely to support positive social objectives (and vice versa). Just as there are positive economy-environment links, there are also important positive links between environmental partnerships and social equity. Since improved environmental management takes social welfare and justice into account, and requires a broader perspective, those societies where the environment is an important element in the public arena, also tend to be more inclusive, irrespective of level of income. This is just as true in Costa Rica as it is in Switzerland or Sweden. Access to environmental goods and services and the choice of being involved in decision making (whether this is exercised or not, participation is also a matter of choice and is not always the desired option for an individual) support the broader concepts of defining poverty and opportunity as defined in the 2001/2002 World Development Report or Amartya Sen's recent writings on Development and Freedom.

7. The increased importance of private investment will determine a country's environmental future. At present private annual investment flows are 20 times as large as those of ODA (Official Development Assistance). This is both an opportunity and a challenge. The opportunity is to work with these very large financial flows to build towards a more sustainable future, while the challenge is to set up incentives/ rules of the game that make private investments part of the process of sustainable development. If governments ignore private flows and just focus on government investments and ODA, they risk winning the (environmental) battle but losing the war. Private sector interventions in water supply and opportunities presented by the Clean Development Mechanism are 
interesting examples of partnering with private interests to achieve desired development and environmental outcomes.

8. The final reason why the environment cannot wait in developing countries is that it is the right thing to do. The poor care about a cleaner and sustainable environment just as much as the rich, but their willingness-to-pay is not matched by their ability-to-pay. Governments, therefore, have a responsibility to invest in the environment and its management, and to establish environmentally-friendly "rules of the game" that influence private individual and corporate behavior. For certain types of issues (e.g. global public goods like genetic stock or greenhouse gas reductions) the global community also has a responsibility to support these investment decisions. This is happening increasingly. While growth continues to be important for developing countries in order to rise out of poverty, this growth should not come at the expense of environmental health and opportunities for the poor.

\section{THE FUTURE CHALLENGE}

In conclusion, the intimate links between environmental quality, environmental management, and economic development, make a strong case for addressing both concerns - the environment and economic growth - simultaneously. This will not happen automatically, however, and there is an important role for government, as well as for an informed public, in making this happen. The responsibility is huge, but the costs of not addressing these issues are even larger. The costs of inaction, as is becoming increasingly clear, are being paid by the more vulnerable and economically disadvantaged groups. Also, such costs will be borne not just by this generation but by future generations as well. It would, in short, be a wasted opportunity for achieving sustainable and equitable patterns of development, if developing countries waited to grow first and address environmental issues later. 